The present thematic test focuses its tie attention on different from the Latin American conservation and the patrimony. Aspects of historical type consider here, like also reflections around the evolution of the patrimonialista legislation in the continent, the creation and trajectory of institutions of patrimony, restoration and study, the revaluation of the Historical Centers and the concept of "cultural surroundings", or the increasing interest by the small towns. It is also approached from a critical perspective, becoming emphasis in several of the problems that must confront the patrimony in Latin America, like the loss of the "urban memory", the political interventions destroying the patrimony (monumental or natural) in entailment to private real estate businesses, or the errors in the interventions of restoration or rehabilitation.

Keywords: Latin America. Conservation. Patrimony 


\section{La Conservacion Y El Patrimonio En America Latina. Algunos Temas De Debate}

\section{Rodrigo Gutiérrez VIÑUALES}

El presente ensayo centra su atención en diferentes temáticas vinculadas a la conservación y el patrimonio latinoamericanos. Se tienen aquí en cuenta aspectos de tipo histórico, como asimismo reflexiones en torno a la evolución de la legislación patrimonialista en el continente, la creación y trayectoria de instituciones de patrimonio, restauración y estudio, la revalorización de los Centros Históricos y del concepto de "entorno cultural", o el creciente interés por los pequeños poblados. Se aborda también desde una perspectiva crítica, haciéndose hincapié en varios de los problemas que debe afrontar el patrimonio en América Latina, como la pérdida de la "memoria urbana", las intervenciones políticas destruyendo el patrimonio (monumental o natural) en vinculación a negocios inmobiliarios privados, o los errores en las intervenciones de restauración o rehabilitación.

Palabras clave: Latinoamérica. Conservación. Patrimo- 


\section{Introducción}

La historia de América Latina ha estado marcada desde hace quinientos años por la influencia de la cultura europea. Los españoles, sobre todo, han dejado su huella artística la cual, combinándose con las formas y manifestaciones locales, engendró un nuevo modelo de civilización.

Por esta razón, y a pesar de la importancia de este contacto EuropaAmérica, la historia del Nuevo Continente ha seguido su propio camino, siendo su situación y su realidad distintas a las europeas.

Estas diferencias deben de tenerse en cuenta si se quiere realizar un estudio adecuado sobre la conservación y el patrimonio americanos. Es más, inclusive entre los propios países americanos existen tales singularidades; no es el mismo caso el del Perú o el de México, con su fuerte tradición cultural indígena y colonial, que el de países más modernos como Brasil o Argentina en donde el patrimonio decimonónico acapara la mayor atención.

Existen también otras diferencias de carácter histórico con respecto a Europa. Se han producido en América ciertos procesos con anterioridad a sus similares en el Viejo Continente. Este es el caso de la desamortización de los bienes de los conventos e iglesias, hecho que España sufre hacia mediados de la década de los treinta del XIX y que en Argentina ya se había producido con el presidente Bernardino Rivadavia en 1822.

Este suceso nos permite pasar a analizar algunos aspectos de la evolución del tratamiento del patrimonio cultural americano durante el siglo XIX.

\section{El patrimonio en América durante el siglo XIX}

La desamortización de bienes en la Argentina durante el gobierno de Rivadavia trajo consigo consecuencias nefastas que dejaron cicatrices durante muchos años. Los conventos y las órdenes religiosas fueron eliminados legalmente pasando los edificios a formar parte del patrimonio nacional bajo la apariencia de que iban a transferirse al clero secular. Este manejo del poder político determinó entre otros aspectos que las ciudades de Buenos Aires, Córdoba y Salta permanecieran sin obispos por largo tiempo. 
En cuanto a los conventos algunos se convirtieron en hospitales, otros en cuadras de tropas y en general quedaron destrozados perdiéndose irremediablemente el patrimonio. El viejo Colegio de los jesuitas en la capital argentina quedó en manos del clero secular pasando luego al Estado quien lo convirtió en el histórico Colegio Nacional de Buenos Aires. He aquí un caso aislado de reaprovechamiento adecuado de un edificio.

En Perú se produjo la desamortización poco después que en la Argentina y ejemplo claro de lo allí ocurrido es la actual situación del convento de San Agustín en el Cuzco que desde aquel momento está en ruinas, las cuales hoy pueden verse justamente en la calle "Ruinas" de la capital cuzqueña.

Otro convento peruano, el de San Francisco de Lima, fue sufriendo una degradación paulatina a través de los años posteriores a aquella desamortización. Era esta, originalmente, una construcción que abarcaba tres o cuatro manzanas, y que fue derribándose por partes para ir abriendo calles. Tal tratamiento llegó al culmen de la destrucción con la apertura de la avenida Abancay hacia principio de los años sesenta de nuestro siglo.

Estos atravesamientos sufridos por San Francisco no solamente terminaron con su antigua situación física sino que también afectaron la idea de conjunto monumental con que había sido planeado y terminaron con su carácter de convento como centro del barrio.

En México la desamortización también trajo efectos negativos. Inclusive el Estado y la Iglesia permanecieron divididos por casi un siglo y medio, produciéndose la ansiada reconciliación recién en la década de los ochenta de la presente centuria. El poder político, entonces, tomó la decisión de devolver a la Iglesia muchos de los bienes apropiados en el siglo pasado.

\section{La evolución de la legislación y el patrimonio en Latinoamérica durante el siglo $\mathrm{XX}$ y sus problemas}

\subsection{Leyes, generalidades y casos}

En el transcurso del siglo XX la conservación y la salvaguarda fueron alcanzando distintas connotaciones en cada país americano, 
dadas aquellas diferencias acotadas en nuestra introducción y la variedad de posibilidades de intervenir en el patrimonio. Mientras unos dieron mayor importancia al tema de los monumentos históricos otros centraron sus esfuerzos en el estudio de los poblados típicos y otros -los menos- en el problema del paisaje urbano, el entorno o el ambiente natural.

De todas formas existieron denominadores comunes dignos de destacarse por ejemplo la concientización respecto de la primordial necesidad de resguardar los testimonios precolombinos. Esto se dio especialmente a fines del siglo XIX y principios del XX, cuando comienzan a valorizarse los ejemplos artísticos coloniales y mucho más adelante, tras la Carta de Quito de 1967, se empieza a tomar en cuenta el patrimonio de los siglos XIX y XX.

En los años treinta, juntamente con la señalada importancia que se da a lo colonial, se dieron diversas normas, leyes y fundaciones tendentes a la conservación del patrimonio. En Brasil en 1927 se creó la Inspectoría de Monumentos del Estado de Bahía a la que siguieron ejemplos similares en otros países como México -leyes de 1930 y 1934 que mencionaban las poblaciones y bellezas tpicas- y Guatemala -creación del Parque Nacional de Tikal en 1955 que incluía la conservación de este centro cultural maya-.

En el aspecto de la legislación también son destacables las leyes de Brasil en 1937 y de Argentina en 1940, claros productos de la VII Conferencia Interamericana celebrada en Montevideo en 1937, en la que se propuso la cooperación entre los países, y el Congreso de Historia de América llevado a cabo en Buenos Aires en el mismo año, en el que se recomendó hacer el inventario de los patrimonios y legislar sobre él.

Brasil, a partir de su ley de 1937, centró su interés en las obras de arte, al contrario que la Argentina que se interesó más por los monumentos. En aquel país fue creado el Servicio de Patrimonio Histórico Artístico Nacional (SPHAN) el cual se dedicó también a la organización de congresos y a la publicación de estudios y trabajos, convirtiéndose en un sistema armado desde arriba hacia abajo, de gran carácter federal. La labor de SPHAN en Brasil fue intensificándose con el tiempo, adaptándose notablemente a los cambios sociales y culturales, no sin graves contratiempos. El presidente Collor de Melo llegó a deshacer prácticamente al SPHAN creando comisiones de 
cultura locales las que puso en manos de funcionarios públicos y burócratas. Esta decisión interrumpió en su momento un positivo proceso de más de medio siglo, poniendo fin a una acertada tarea federativa y evidenciando nuevamente la triste realidad de la negativa intervención política en asuntos de Patrimonio que en diversas épocas tuvieron los gobiernos.

La ley de 1940 en la Argentina basó sus artículos en los de las leyes de Francia, Inglaterra, Bélgica e Italia. La Comisión Nacional que se creó a partir de ella habría de encargarse de realizar los inventarios, restauraciones, publicaciones, declarar los monumentos nacionales y organizar museos. Los problemas de fondo, los directos, se quedaron, no obstante, sin resolver.

La evolución de la legislación del Patrimonio en la Argentina a partir de 1940 ha conducido a la situación actual en que las leyes son insuficientes. En varios municipios existen reglamentaciones generales y otras de casos más particulares. Muchas de ellas están redactadas con un lenguaje romántico tendiendo más a una expresión de deseos que a otra cosa.

A nivel provincial hay en Argentina otras leyes de carácter general pero que presentan notables falencias. De todas maneras se han producido ciertos avances como el de Tucumán, provincia que tras el advenimiento de la democracia en 1983 aprobó una nueva Constitución Provincial en la cual fue introducido el tema de la Conservación del Patrimonio.

En ese mismo año se aprobó a nivel nacional una ley en la que se establecía que todo edificio de más de cincuenta años perteneciente al Estado -aunque también sugiere que se haga lo mismo con los de propiedad privada- no puede ser alterado en su estructura sin la vista y autorización de la Comisión Nacional de Monumentos. Lamentablemente esta regla no se aplicó en la realidad y así los argentinos vimos caer, entre otros ejemplos, parte del convento de Santa Catalina de Buenos Aires, construcción de principios del siglo XVII, para dar lugar a edificios nuevos.

Otro ejemplo en la capital argentina es el de la conocida como Manzana de San Juan, centro de las monjas clarisas, en la convergencia de las calles Alsina y Chacabuco, que se demolió para dar cabida a un moderno hotel. 
Durante los años cuarenta hubieron otros países latinoamericanos que legislaron sobre su patrimonio, tales los casos de Venezuela (1945) y Guatemala (1947). El de este último país puede considerarse el ejemplo más completo de legislación a lo largo del siglo con la creación de la Comisión Nacional para Antigua de Guatemala (CNPAG) en 1969 la cual controla entre otros aspectos las acciones de los ayuntamientos, indicándoles donde deben colocar un cartel, donde poner una escultura, etc. Para llevar a cabo su tarea CNPAG ha hecho hincapié en la necesidad de concientizar a la propia población, siguiendo de esta manera con una de las ideas ya esbozadas en el Convenio Italiano de Gubbio de 1960.

La conservación y restauración del patrimonio, que en un primer momento se había reducido a la preservación e intervención en sitios relacionados con la vida o hechos de próceres, cambiaron su sentido durante los años cuarenta, momentos en que pasó a tener mayor importancia el patrimonio artístico. A partir de aquí puede hablarse de un cambio fundamental en ciertos conceptos como el de patrimonio histrico reemplazado ahora por esa idea de patrimonio artstico.

Un nuevo cambio de pensamiento habría de producirse en los setenta. En ese momento quedó ya en evidencia que el patrimonio estaba más allá de un prócer o de un monumento artístico: a este debía considerárselo como parte de un proceso histórico. Aquí podemos señalar como ejemplo la importancia que tomó en la Argentina Virasoro, máximo representante del movimiento Art Decó en ese país, cuyas obras fueron discutidas pero a la vez fue reconocida su validez como testimonio histórico.

Como corolario podemos afirmar que la legislación en América es en general insuficiente y con muchos baches lo que permite a las "aves de presa" de la construcción y la política accionar casi libremente sobre el patrimonio, por lo cual es constante el peligro en que este se encuentra.

\subsection{Uno de los problemas: la pérdida de la "memoria urbana"}

En numerosas ocasiones se ha procedido lamentablemente a deshacer las obras que marcaron los rasgos artístico-arquitectónicos 
de una época, ya sea porque estas "estaban pasadas de moda", ya sea por la "fiebre" de construir o por la de "destruir" todo testimonio de regímenes políticos pasados.

Otra manera muy habitual en América de prdida de la memoria urbana es el constante cambio, en muchas ciudades, del nombre de las calles. En Resistencia (Argentina) sucedió, entre otros casos, con la actual calle Arturo Illia. En diversos períodos de su corta historia -apenas sobrepasa el siglo de existencia- se llamó Edison, en honor al sabio; Uruguay, como homenaje a nuestros hermanos orientales; Eva Perón, cuando la mujer del presidente era el personaje más carismático del país; Antártida Argentina, poco después de la revolución que derrocó a Perón; y, finalmente, desde hace poco más de diez años, ya recuperada la democracia luego del Proceso militar, se llama Arturo Illia.

En esos años el bloque de concejales peronistas del Municipio de Resistencia había cambiado el nombre de la calle Tucumán, la continuación de Antártida Argentina, por el de Juan D. Perón (otro caso de pérdida de la memoria urbana). Sus grandes rivales de la Unión Cívica Radical no querían quedar en "inferioridad de condiciones" y comenzaron a buscar un nombre para cambiar el "añejo" de Antártida Argentina, la otra calle comercial junto a la nueva Juan D. Perón- de Resistencia.

En ningún momento repararon ni unos ni otros en el hecho de que quienes habían colocado aquellos nombres, Antártida Argentina y Tucumán, lo habían hecho con alguna razón -ni hablar de los anteriores nombres-. El hecho es que los radicales buscaron recuperar alguna de sus figuras e "inmortalizarlas" en el asfalto. Las dos más grandes, Hipólito Yrigoyen y Marcelo T. de Alvear ya tenían sus calles; el ex-presidente que les quedaba era Arturo Illia y a él eligieron.

Además del cambio del nombre de las calles, otra de las maneras de ir borrando la memoria urbana es la de los proyectos llevados a la práctica que arrasan con lo existente y tergiversan el sentido urbano. En Caracas encontramos el caso quizá más grave del continente con la construcción de grandes autopistas y el entubamiento de los ríos, acciones que han cambiado la antigua fisonomía de la capital venezolana.

Otro caso, aunque este fue ya más lejos pues se trató lisa y llanamente de un cambio en la propia topografía del lugar, es el que ocurrió en Río de Janeiro en la época del gobernante Pereira Pasos a fines del siglo XIX y principios del XX, quien ordenó que dos de los morros que se 
encontraban en la bahía fueran eliminados mediante una "tajada" en diagonal.

\subsection{Cambios producidos a partir de la Carta de Venecia (1964) y las Normas de Quito (1967)}

Durante la década del sesenta vieron la luz los dos documentos fundamentales que sentaron las bases para el cambio del status quo de la legislación y el patrimonio en América Latina: la Carta de Venecia de 1964 y las Normas de Quito de 1967.

La primera de ellas fue rubricada por dos jóvenes latinoamericanos que se hallaban estudiando en Italia, el peruano Víctor Pimentel y el mexicano Carlos Flores Marini. Ciertas recomendaciones que allíse hicieron representaban toda una novedad para América: la documentación histórica, el turismo cultural, el respeto por todas las etapas de la obra, el tratamiento conservacionista y no reproductor, etc.

En cuanto al documento de Quito es más amplio en su articulado respecto al de Venecia y en el se detallan problemas específicos de Latinoamérica. Participaron de las reuniones en la capital ecuatoriana especialistas americanos y españoles quienes se plantearon la necesidad de vincular nuevamente a los países del Nuevo Mundo con España y Portugal, de valorar el Patrimonio de los siglos XIX y XX y de accionar en el aspecto técnico.

Las Normas de Quito tendieron más a una cuestión de tipo urbanístico y de manejo político del patrimonio. Su alcance es de mayor escala -sin ser completamente específica de América- que la Carta de Venecia cuyo hincapié fue mayor en temas de patrimonio y conservación.

Hasta estos momentos no se había tenido demasiado en cuenta el concepto de "monumento histórico" comprendiendo la creacin histrica aislada as como el conjunto urbano o rural (Carta de Venecia, art. 1). Esta valorización del entorno se dio tardíamente, cuando ya habían sucedido casos como el de San Diego de Bogotá: el pequeño convento se preservó pero no se cuidó el espacio que lo rodeaba y hoy apenas se puede ver entre grandes autopistas y hoteles.

Un ejemplo similar es el de Villa Hortensia en el Barrio Alberdi de Rosario (Argentina), una quinta de verano de principios de siglo, al estilo de las de Mar del Plata, edificio que en los años ochenta 
de nuestro siglo se declaró Patrimonio Histórico. Lamentablemente la manzana que lo rodeaba se loteó y esta construcción que había dado origen al barrio y que sus dueños habían armado a la manera de un pequeño pueblo, en la actualidad ya se halla unida a la ciudad, "aprisionada" entre modernas muestras de arquitectura.

Volviendo a las Normas de Quito, este documento hará que países como Brasil, Cuba, Chile, México y Guatemala pongan al día sus legislaciones. Se reiniciaron las tareas inventariales y se dio impulso para la formación de técnicos intervencionistas y la organización de talleres y laboratorios. No obstante este ímpetu inicial varios países del continente continuarán con legislaciones anacrónicas, especialmente los centroamericanos. Otras naciones aprobaron leyes sobre el patrimonio pero sin llegara a aplicarla. En este sentido el caso más evidente es el de Perú, y en menor medida el del ya señalado México.

\subsection{El caso de los "Centros Históricos"}

En Perú los casos de los centros históricos como Lima, Cuzco, Arequipa y Trujillo son patéticos. Esta última ciudad posee una estructura de manzanas cuadradas que en la época colonial estaban ubicadas dentro de una muralla de tapia -típica de regiones secas, de poca lluvia- de forma octogonal y alargada. Esta muralla no fue respetada en el siglo XX; parte de ella se tiró para dar cabida a edificios modernos y otra se utilizó como basamento para los mismos. Lo que más sorprende en este caso es que el autor de tal aberración fue un arquitecto de la propia Trujillo relacionado con el INC (Instituto Nacional de Cultura).

En definitiva, las leyes de protección existen pero no son respetadas. Lo mismo ocurre, como vimos, con el concepto de "Centros Históricos" respecto de que son tanto patrimonio cultural de la humanidad como que pertenecen en forma particular a todos aquellos sectores sociales que los habitan y con ellos se debe procurar una poltica de conservacin integral, tal como se especificó en las conclusiones del Coloquio sobre la preservacin de los Centros Histricos ante el crecimiento de las ciudades contemporneas, celebrado en Quito, en marzo de 1977.

\subsection{El problema de la intervención política en asuntos}




\section{de patrimonio}

Otro de los males que han sufrido varios países americanos es el de la derogación de artículos por conveniencia política. Como casos de esta realidad se pueden señalar:

1) los Monumentos declarados "históricos" a los que se les priva luego de tal condición para poder alterarlos en parte o demolerlos. Ejemplo de ello es el ocurrido durante los últimos gobiernos militares en Uruguay donde numerosos edificios públicos, escuelas antiguas -que se derribaron para hacer edificios nuevos- y otros monumentos fueron intervenidos con el único fin de hacer negocios;

2) las leyes que se derogan en partes. Este es el caso de lo ocurrido en el Centro Histórico de Corrientes (Argentina). Desde 1977 -ya en época de gobierno militar- existía una "Ordenanza Histórica" que en diversas ocasiones fue modificada -a veces solo por un día !- para que pudieran realizarse obras nuevas, las que encontraban en los monumentos antiguos un estorbo.

Así un día se presentaba un proyecto; al comprobarse su inviabilidad por "culpa" de la "Ordenanza Histórica", se anulaban las normas de esta que imposibilitaba la realización de aquel; una vez que el proyecto se encontraba dentro de la legalidad, sin el condicionamiento de la "Ordenanza", era aprobado y al siguiente día se reinstauraban las antes anuladas reglas de la "Ordenanza".

Lamentablemente, por lo visto en numerosos lugares y épocas de América el concepto de "Bien Común" no tuvo ni tiene ningún valor. La política del liberalismo consistente en que el que tiene dinero hace lo que quiere arrasa con tal concepto. A veces los americanos agradecemos el que no haya habido dinero en el continente porque con él se habrían podido llevar a cabo muchos de los proyectos que se presentaron a lo largo del siglo y la historia de nuestro patrimonio artístico probablemente sería más dolorosa.

En este sentido es de lamentar el caso de Venezuela, país que tradicionalmente ha contado con dinero y que ha intervenido en sus monumentos históricos con muy mal tino, perdiendo en las últimas décadas gran parte de su patrimonio. 


\section{Problemas de intervención en el patrimonio de América Latina}

\subsection{La búsqueda mal entendida de "nuestras raíces". La pérdida del patrimonio americano durante el siglo $X X$}

En América y especialmente en los países del sur como Argentina o Uruguay, de menor tradición colonial y más influídos por las inmigraciones y por lo tanto por la cultura europea de fines del siglo XIX y principios del XX, siempre se pensó como modelo a una Europa a la que se veía como culta, como una unidad.

El gran desconcierto surgió al producirse el estallido de la primera Guerra Mundial; con gran incredulidad se vio en América la lucha entre países cuya imagen era justamente aquella, de que estaban unidos. Esta situación aceleró el proceso de ver los distintos aspectos de la vida desde un punto de vista más americano.

Con la guerra quedaron también interrumpidas las importaciones de los países americanos respecto de los productos que recibían de Europa; esto produjo un repunte de las industrias nacionales.

Dentro de este proceso de "americanización" comenzado en aquella época y que hoy continúa, algunos países comprendieron como necesidad, respecto de lo urbano, el "llegar a lo original". Aquí volvemos sobre el tema de la memoria urbana. Se atentó y se sigue atentando contra una de las normas de la Carta de Venecia consistente en que las aportaciones de todas las pocas patentes en la edificacin de un monumento, deben ser respetadas, dado que la unidad de estilo no es el fin que se pretende alcanzar (art. 11), a menos, agrega, que los elementos que quieren eliminarse ofrezcan poco inters.

Entre los ejemplos de vejación a estas ideas podemos señalar el de la República Dominicana. En los años setenta surgió en Santo Domingo la obsesión de que había que recomponer la "cara" del siglo XVI en el centro histórico. A una de las casas de esa centuria comprendidas en este perímetro se le habían añadido distintos "ropajes" a lo largo de los siglos y su coronación definitiva era el último ejemplo que quedaba en la capital dominicana del art nouveau. La idea de regresar al XVI terminó por ser más fuerte y tal art nouveau se perdió irreparablemente. 
Cosas similares se hicieron muchas veces en sitios arqueológicos. Recién en los años setenta los arqueólogos fueron formados como "cuidadores de ruinas" sobre todo en México y Perú. Anteriormente estos profesionales se limitaban a excavar pero no a consolidar, a asegurar las condiciones de conservacin (Carta de Venecia, art. 15), a proteger los hallazgos que se iban produciendo en las tareas de campo.

La consolidación en ejemplos arquitectónicos data de los años posteriores a la primera guerra mundial. En lugares como las misiones franciscanas de California, cuyo ejemplo se siguió en otras zonas de América, se dio una suerte de romanticismo, consolidándose las ruinas pero con el carácter de ruinas, es decir se consolidaron las roturas, las caídas de revestimiento, la falta de revoques en la punta de los dinteles, etc.

\subsection{El caso de los "templetes" y los "cambios de clima"}

Otra de las actitudes fue la de no tocar las obras protegiéndolas mediante un templete para que no se deterioraran más el cual alteró el ambiente que rodeaba el monumento. De esto podemos señalar numerosos ejemplos pero citaremos tres en la Argentina:

1) el templete de hierro y vidrio erigido a fines del siglo XIX para proteger la habitación de la Casa Histórica de Tucumán, lugar de la Declaración de la Independencia Nacional en 1816, y que fue derribado durante los años cuarenta por Mario J. Buschiazzo al emprender la reconstrucción del monumento en casi su totalidad;

2) el templete construído en la época del art decó que protege la casa natal de Fray Mamerto Esquiú en la provincia de Catamarca;

3) el templete que protege la mal atribuída casa natal del General don José de San Martín en Yapeyú (Corrientes) y que fue construído en los mismos años en que Buschiazzo derribaba el de Tucumán.

Con obras como las señaladas el monumento queda desvirtuado en cuanto al espacio y al entorno. Esta mal entendida protección atenta además contra el microclima de la obra, con los materiales originales los cuales fueron utilizados pensándose en la acción directa del sol, los vientos, las lluvias, etc. En el caso de la 
Casa de Yapeyú, los insectos, ya sin estos "problemas" del clima, han ido degradando las piedras de las ruinas.

Estos "cambios de clima" hechos por el hombre no son privativos de nuestro siglo. Ya en el siglo XVI, cuando los españoles convirtieron a Lima en capital del Perú en detrimento del Cuzco, antigua capital del imperio incaico, trasladaron desde el templo cuzqueño de Coricancha a Lima las momias de los 14 incas que se habían conservado allí desde hacía años.

En Lima, con un clima distinto al de Cuzco, las momias alcanzaron un grado de putrefacción en menos de una década perdiéndose de manera definitiva tales testimonios.

\subsection{El agregado de partes nuevas y la incorporación de elementos acordes con el "gusto actual"}

El tema de las partes agregadas, tanto en lo que se refiere a su inclusión como a la forma de añadirlas, ha dado lugar durante años a numerosas polémicas debido a que existieron y existen diversas visiones sobre cómo encarar este tipo de problemas. No obstante las opiniones encontradas en general los especialistas coinciden en la necesidad, para una correcta adecuación, de utilizar avances modernos como los acondicionadores, los sanitarios o la electricidad.

En los años setenta surgió el concepto de que ese agregado de partes nuevas debía hacerse en estilo, es decir copiándose las formas del resto del edificio en intervención, tratando a la vez de que se notaran lo menos posible los fragmentos nuevos.

Aquí podemos señalar los trabajos llevados a cabo en Arequipa (Perú) durante esa década en donde se rehicieron edificios imitando lo antiguo, como en el caso del patio de la Compañía de Jesús.

A pesar de las buenas intenciones que se tengan en este sentido es fundamental que se dejen también, discreción mediante, las señas de los nuevos tiempos, tal como hemos señalado en el primer párrafo de este punto.

En España podemos señalar un caso notorio de esta imitacin de lo antiguo y que es la Sagrada Familia de Barcelona, la cual fue planteada por Gaudí de manera tal que todas sus partes y detalles 
fueran artesanales. Luego de su muerte la construcción se continuó copiando literalmente las partes ya existentes, siguiéndose un erróneo concepto simétrico, alejado de la idea original de Gaudí.

Derivado de los aspectos de restauración y tecnología surge también un problema de notoria actualidad: la incorporacin a los monumentos de elementos acordes con el gusto actual. Este tema que se ha planteado en España sobre casos como el de las ruinas del Teatro romano en Sagunto, está signado por el afán de ciertos profesionales de imitar formas consagradas por los medios de comunicación quienes demuestran una total falta de identificación con el patrimonio y no han entendido que la tarea del restaurador ha de ser, en buena medida, anónima.

\subsection{El deseo de resaltar los materiales naturales y las texturas}

Otra de las equivocaciones en las que se cayó a la hora de restaurar fue la de quitar a los edificios antiguos los revoques y estofados para resaltar los materiales naturales y las texturas. Con ello no solo se perdieron pinturas murales y molduras sino que también se evitó que partes que originalmente sí habían sido preparadas para estar al descubierto pudieran distinguirse del resto del conjunto.

Esto fue lo que ocurrió con varias portadas de cantería en el Cuzco en la época de reconstrucción que siguió al terremoto de 1950. Tales portadas que debían resaltarse sobre el muro blanqueado hoy se confunden con la tosca mampostería de piedra que ha quedado a la vista a su alrededor. Como casos podemos señalar los de la puerta de San Antonio Abad y la iglesia de Santa Clara, en donde por esa búsqueda del "material a la vista" se perdieron varias de las pinturas murales que cubrían las paredes del templo.

Distinto fue el tratamiento que se siguió en las obras coloniales de lugares como Salvador de Bahía (Brasil), en donde se respetaron las fachadas de los edificios pero se reconstruyeron totalmente los interiores. Las fachadas se convirtieron así en meros telones ornamentales detrás de los cuales pueden encontrarse cosas 
inverosímiles.

Entre tantos inconvenientes no deben dejar de señalarse aspectos positivos como las buenas actitudes entre ellas la humildad de los viejos arquitectos que intentaron ponerse al día con los nuevos postulados y la conciencia que se fue tomando respecto del valor de los monumentos antiguos, especialmente de los coloniales.

\section{Temas derivados de las Cartas de Venecia y Quito}

\subsection{El panorama general del patrimonio americano a partir de la Carta de Venecia de 1964}

El hecho de que dos latinoamericanos hubieran rubricado la Carta de Venecia en 1964 no significaba que sus postulados fueran los que hasta ese momento seguían los arquitectos restauradores en el continente, cuyas características se acercaban más a la de los "amantes de lo antiguo" y a la de los historiadores.

Las ideas que aun primaban en América Latina tendían más bien a considerar que el único patrimonio rescatable era el anterior a la época de la Independencia; se seguía pensando en el monumento aislado y no en el entorno (salvo excepciones como alguna misión religiosa o sitio precolombino), etc.

La Carta de Venecia tuvo su difusión en América a través de revistas como los Anales del Instituto de Arte Americano de Buenos Aires o el Boletín del Centro de Investigaciones Históricas y Estéticas de Caracas. En Perú fue difundida por Pimentel quien hizo un glosario de artículos de la Carta para ser aplicados en el país, el cual encontró oposición en un arquitecto que escribió la titulada "Mi Carta de Lima".

Quien escribió "Mi Carta de Lima" era un neocolonialista que entendía el manejo del patrimonio desde su particular punto de vista. Fue el constructor del Hotel de Turistas del Cuzco en los años treinta, un edificio neocolonial para cuyo levantamiento fue necesario derribar un edificio auténticamente colonial. 


\subsection{Las Normas de Quito y la importancia del entorno}

La concientización del valor del patrimonio tomó otro matiz en 1967 con el surgimiento de las Normas de Quito. Se cambió el viejo concepto de que el carcter histrico de un lugar estaba dado por si allí se había producido algún hecho de relevancia (el nacimiento de un prócer, la firma de algún tratado, el libramiento de una batalla, etc.). A partir de ese momento tomó importancia la idea de lo estético independientemente de lo histórico; se comenzó a valorar el monumento como obra de arte y el monumento y su entorno, no como edificio aislado.

Para esta entonces muchos entornos ya habían sido cambiados en su fisonomía, generalmente de dos maneras, o variándose el tamaño de los edificios -la mayoría de más tamaño que los existentes- o alterando las características físicas de los mismos afectando así el sentido estético original. Inclusive en la actualidad continúan haciéndose desastres en este sentido. Hay sectores urbanos cuyas fisonomía y arquitectura son coloniales, y en donde antiguamente se planearon calles angostas para permitir que la sombra cobijara tales arterias y en las cuales pudiera correr el aire. Con el advenimiento de las "modernidades" se ha visto desaparecer edificios reemplazándoselos por antejardines modificando toda aquella concepción.

Como ejemplo podemos señalar el Banco construído en la calle Leandro N. Alem de Buenos Aires que cuenta con un amplio antejardín y por lo tanto está sometido a una acción mucho más directa del sol, primitivamente no planeada. Además de esta manera se atenta contra una normativa existente que manda que las casas de la vereda oeste de la calle Alem deben poseer soportales (galerías o recovas) a la manera antigua.

Finalmente el prestigioso arquitecto constructor del Banco, casi con carácter de "intocable" entre sus colegas, debió dar marcha atrás y colocar unos soportales que actualmente cubren la vereda, la cual de esta manera se encuentra siempre bajo techo. 


\subsection{La revalorización de los Centros Históricos y el interés por los pequeños poblados}

Este movimiento de revalorizacin de los Centros Histricos se produjo justamente después de la Carta de Venecia; antes solamente se tenían en cuenta las ciudades antiguas como Cuzco o Antigua. A partir de Venecia se valorizaron centros como los de México, el Barrio de San Telmo en Buenos Aires, la Lima "cuadrada" -la colonial, trazada en cuadrícula-, etc.

Luego de Venecia surgió también el interés por los pequeos poblados histricos. Se empezaron a estudiar problemas como el de la incidencia del turismo sobre ellos y la necesidad de no verse absorbidos por este. También se presentó el problema de la tugurizacin de los centros antiguos, tema en el que durante los setenta la propia Unesco llegó a tener injerencia al enviar a hacer trabajos en Cuzco, Quito y Salvador (Bahía). Posteriormente se fue pasando a otras ciudades de menor tradición pero poseedoras también de un rico patrimonio como Montevideo, Catamarca (Argentina), Bogotá, etc.

El tema de los pequeños poblados no ha sido hasta hoy estudiado con profundidad. La Unesco, no obstante, ha mostrado su interés en ellos a través de publicaciones como las del programa que Sylvio Mutal condujo en Lima, el cual ha editado una obra titulada justamente Pequeos poblados en donde se hace un estudio de los mismos en el Perú.

Más allá de los logros aislados en el plano práctico que se fueron produciendo en América Latina después de Venecia, debe tomarse como una conquista el hecho de que estos temas se convirtieran en objetos de análisis.

\subsection{La conservación del patrimonio, la restauración y las tecnologías}

Nuevas investigaciones sobre el patrimonio y su conservación fueron iniciadas a partir de Venecia. Se puso en evidencia la preocupación de profesionales de áreas distintas a la de la restauración directa (economistas, abogados, etc.) respecto de 
lo mismo y los equipos de planificación urbana fueron de a poco incorporando a sus labores estos temas.

El propio monumento empezó a ser tratado de otro modo, teniéndose en cuenta todas sus etapas de construcción. Se estudiaron los materiales y las tecnologías tradicionales además de otros problemas que antes no se habían abordado. Se comenzaron a diferenciar la restauración de la conservación y de la reconstrucción.

Esto obviamente no fue practicado en su totalidad ni en todas las zonas. En varios lugares se utilizaron materiales actuales para la restauración sin tenerse en cuenta los originales, por ejemplo en la iglesia de Molinos en Salta (Argentina), que construída primeramente en adobes sufrió una restauración con hormigón armado. También es el caso de la casa de Nicolás Avellaneda en Tucumán cuya estructura original era de madera y fue restaurada con estructuras metálicas.

La restauracin de arquitecturas de tierra con cemento se ha vuelto algo habitual y generalmente negativo en América Latina. Otro caso es el de las pinturas inadecuadas que se utilizan en las intervenciones. Las paredes de tapia del Capitolio de Caracas hoy se encuentran "enmascaradas" con materiales sintéticos lo cual hace necesarias continuas restauraciones.

En el campo de la tecnología la realidad muestra un descenso marcado de intervenciones con uso indiscriminado de los nuevos materiales teniéndose más en cuenta las soluciones tradicionales a base de adobe, piedra, madera o caña, ahora recuperados para la construcción. Más allá de cierto romanticismo se han sabido ver su utilidad y menores costos. Lo mismo ha ocurrido con el correcto uso que no contados profesionales han dado al ladrillo.

Finalmente debe señalarse otro aspecto de imperiosa importancia como es el del uso posterior del edificio o monumento y su manutención. Las restauraciones deben hacerse teniendo en cuenta cual será el uso posterior que se dará al edificio. Debe organizarse además el mantenimiento, designándose responsabilidades, de tal manera que no ocurran casos como el del Fuerte de Cobos en Salta (Argentina) que tuvo que ser restaurado tres veces en los últimos cuarenta años por carecer de una utilización práctica y del cuidado necesario. Justamente el fomento de la conservación y el mantenimiento fue uno de los temas en que puso especial énfasis 
la Campaña Europea para el Renacimiento de la Ciudad de 1981 en su apartado sobre Rehabilitación de inmuebles y barrios antiguos.

\subsection{Las intervenciones en pintura y escultura}

Además de la restauración y conservación de los edificios comenzaron a tenerse en cuenta a partir de Venecia y Quito elementos complementarios de los monumentos especialmente las obras de arte pictóricas y escultóricas.

América Latina es rica en cuanto a testimonios coloniales de pinturas de caballete y la talla de imaginería y retablos. Habitualmente se piensa que por ser estos objetos de arte móviles pueden cambiarse de lugar sin alterar la arquitectura; las evidencias han demostrado lo contrario.

En los últimos años la tendencia ha marcado que las tareas de conservación y restauración se acometieron de forma paralela, gracias a lo cual se han abandonado en gran medida estos cambios de sitio y hasta inclusive las mutilaciones, como ocurriera en el XIX con las tallas de las vírgenes en Buenos Aires que se recortaron para poder ser vestidas a la manera neoclásica o las columnas barrocas de Paucartambo en el departamento de Cuzco que fueron alisadas y pintadas.

Las pinturas murales son merecedoras de un tratamiento preferente y más cuidadoso que las de caballete por el hecho de que son parte de la misma arquitectura. Para su restauración se hace necesario el reacondicionamiento previo de los muros que la soportan. El criterio a seguir debe ser el mismo que en la arquitectura, es decir la conservación de las distintas etapas de la obra.

En las dos últimas décadas el descubrimiento de este tipo de pinturas se ha multiplicado asombrosamente en Latinoamérica, ya no solo de la época colonial sino también del siglo actual hasta nuestros días, sobre todo en zonas semirrurales. A este tema de las pinturas murales ha de agregarse el de las tallas en piedra o madera adosadas a la arquitectura, muy comunes en América; valiosas piezas de este tipo han sido sustraídas de sus lugares originales mutilando el sentido de conjunto. 


\subsection{Los centros de restauración y estudio}

Una de las premisas de la Carta de Venecia y que fue luego reafirmada en las Normas de Quito fue la necesidad de crear centros que cubriesen las necesidades técnicas a fin de llevar a cabo las tareas de conservación. A estos centros podemos dividirlos en tres grandes grupos: los talleres y laboratorios, los cursos de formación y los centros de inventario.

En cuanto a los talleres y laboratorios podemos destacar en América Latina el trabajo del Consejo Nacional para la Protección de la Antigua Guatemala que desde 1969 viene trabajando en restauración, complementando las tareas directas con otras menores pero no menos importantes como la labor de estudiantes a través de los cuales se llega a una concientización de las familias, la realización de estudios ecológicos botánicos y sísmicos, etc.

El Proyecto PER 71/539 en Perú fue una muestra de la ayuda dispensada por la Unesco a países latinoamericanos durante los años setenta, en este caso uno de los dos con mayor raigambre hispánica. El trabajo consistía en un estudio a realizarse durante siete años sobre 27 monumentos tanto precolombinos como coloniales. Para los primeros eran necesarias las tareas arqueológicas.

EI PER 71/539 organizó durante su existencia un sistema de talleres y laboratorios que luego siguieron su labor bajo la dirección del Instituto Nacional de Cultura. Mientras el taller de objetos muebles trabajaba sobre imágenes y pinturas, otros especialistas lo hacían sobre pinturas murales. Era este un lógico complemento a los trabajos de arquitectura y arqueología.

A su vez el PER 71/539 estaba relacionado con el Plan COPESCO surgido también a mediados de los años setenta, y cuyo objetivo estaba centrado en los departamentos de Cuzco y Puno. COPESCO puede señalarse como una idea derivada de la Carta de Quito de 1967 ya que su finalidad primordial era la de promover el turismo cultural, consistiendo el trabajo en obtener y reinvertir dinero en el patrimonio.

Esta "explosión" turístico-cultural en el Cuzco trajo consigo varios inconvenientes no previstos en un principio, tal como ocurre en las muy visitadas ruinas de Machu Picchu en donde se ve constantemente a la gente caminando libremente por los andenes 
incaicos, cuya estructura no está preparada para soportar el peso de tanta humanidad.

Inclusive los propios organizadores del "boom" atentaron contra el patrimonio en su afán ilimitado de erigir una infraestructura hotelera adecuada y de abrir carreteras en zonas localizadas, entre otros menesteres. Concretamente, al trazar en el terreno la ruta Sicuani-Puno no tuvieron compasión con sitios arqueológicos a los que, en comparación con otros más importantes, consideraron en aquel entonces de segundo o tercer nivel.

En lo que a los cursos de formación respecta, es tema que puede ir enlazado con los referidos anteriormente sobre el Proyecto PER 71/539, plan en el que se incluyeron cursos de formación técnica con el apoyo de la Unesco y la OEA.

A nivel universitario pocas son las facultades en Latinoamérica que actualmente incluyen materias sobre patrimonio y conservación. No obstante en los últimos años se ha ido incrementando la oferta de cursos de posgrado como los de las universidades de Bahía (Brasil) -quizá los más prestigiosos-, la de México y la Universidad Católica de Córdoba (Argentina).

Fuera del ámbito universitario existen centros de trabajos que también han organizado cursos de formación. Caben señalar los organizados por el Centro Paul Coremans en México. De él han salido en los últimos treinta años numerosos especialistas de América.

Un problema más grave aun que la limitada oferta de cursos de formación en Latinoamérica es el hecho de que un gran número de estos profesionales que gozan de la posibilidad de perfeccionarse en el exterior al regresar a sus respectivos países no obtienen una conveniente reinserción en el mundo laboral. De esta manera estos nuevos especialistas en conservación e intervención en pintura, escultura y arquitectura se ven relegados en las responsabilidades de primer nivel por funcionarios públicos y otros "aficionados" a las antigüedades.

Como se puede apreciar también en América Latina existen problemas y conflictos similares a los planteados en el programa de "Legislación y Patrimonio" en el capítulo referido a La redefinicin de la oferta cultural en la Espaa de los ochenta, como ser este de la formación de personal técnico en el ámbito de la conservación. 
Pueden señalarse también aquí la insuficiencia de los programas de rehabilitación, el estado entre la terciarización y el abandono de los centros históricos y el problema de los espacios públicos y las periferias, sobre algunos de los cuales hemos hablado.

Pasando al tema de los centros de inventario, indicar que el trabajo de inventariado se inició en Latinoamérica a principios del siglo XX y ya para los años veinte tenemos conocimiento de diversas publicaciones al respecto. En los tres últimos decenios de la centuria estas tareas se acrecentaron, catalogándose edificios y zonas urbanas de manera sintética y orgánica en todo el continente.

El tema de los inventarios es de suma importancia ya que cumplen la función, previa a la intervención, de ver lo que existe. Los inventarios pueden ser de enumeracin (simple cómputo de lo existente) o razonados (calificando el estado de los monumentos $u$ objetos, incluyendo los problemas que puedan llegar a sufrir).

El modelo utilizado para las labores de inventariado han sido las fichas del Consejo de Europa. Luego de una etapa inicial de primeras experiencias y reuniones en Colombia, México, Chile y Costa Rica en las cuales se trató el tema, se fueron paulatinamente aunando los criterios respecto de la ejecución de aquellas tareas.

En el primero de esos países se montó un importante Centro de Inventario que sirvió de ejemplos a otros que vinieron después en Sudamérica. Además de los monumentos comenzaron a tenerse en cuenta los objetos de arte, las partituras musicales, los documentos y libros antiguos y otras manifestaciones de propiedad pública y privada que quedaron registradas en la institución.

En Brasil se han hecho tareas similares, incluyendo publicaciones en los estados de Bahía y Minas Gerais. Lo mismo México, cuyas tareas hoy se sistematizan a través del Instituto Nacional de Bellas Artes (INBA). En ese país se han realizado catálogos sistemáticos de monumentos nacionales, estado por estado, estudios que continúan publicándose en la actualidad.

La otra cara de la moneda es la mostrada por Argentina donde el Comité Nacional del Icomos ha perdido tiempo y recursos sin aprovechar la oportunidad de inventariar, manteniendo prácticamente sin uso varios equipos de máquinas procesadoras. Esto es un indicativo de la técnica sola es insuficiente y que el trabajo de base -más lento y menos espectacular- también es necesario. 
Por último cabe señalar que además de los inventarios de obras muebles e inmuebles señaladas, últimamente se están encarando los de materiales y sistemas tradicionales de construcción, es decir las estructuras de piedra, madera, caña, tierra, etc. Esto se ha vuelto de imperiosa necesidad para la rehabilitación de edificios y para la mayor conservación de los ámbitos urbanos.

\section{La intervención en el patrimonio latinoamericano. Temas actuales de debate}

El tema de los inventarios, que ya fue incluido en el capítulo anterior al ser tratados los diferentes tipos de centros de formación surgidos tras la Carta de Venecia por lo cual no volveremos sobre las mismas consideraciones, debe incluirse también aquí como una de las formas de intervención de actual necesidad en el continente americano.

A dichos trabajos de inventariado podemos sumar otras dos tareas de vital interés como son la de las obras de conjunto y la recuperación integral del patrimonio.

En lo que respecta a las obras de conjunto debemos señalar como importantes las numerosas tareas de este tipo desarrolladas en Quito luego del terremoto de 1980. Las mismas contaron con el apoyo de España y más concretamente de "Cooperación Española", cuyos técnicos supieron respetar los conocimientos de los especialistas locales. Así, mientras estos se dedicaron sobre todo a los trabajos arqueológicos, los españoles intervinieron más en las obras de arte. Tal fue el caso de las obras realizadas en San Francisco de Quito, quizá la más importante intervención de las que se concretaron durante los ochenta en la capital ecuatoriana.

Con el asesoramiento de "Cooperación Española" se creó también la "Escuela Taller Angostura" de Ciudad Bolívar (Venezuela), cuyo objetivo fundamental es la formación de artesanos de la construcción. Los nuevos especialistas que van surgiendo trabajan en la rehabilitación de edificios de esa ciudad practicando en las propias obras lo aprendido.

El tema de la recuperación integral en América Latina se desarrolla en un plano mucho más modesto que en Europa donde 
las posibilidades económicas son notoriamente superiores. Como ejemplo en nuestro continente podemos tomar el del Servicio Nacional de Arquitectura que interviene en el patrimonio histórico-artístico del Noroeste argentino, zona en donde se reparte labores juntamente con la Fundación Tarea, la cual cuenta sobre todo con especialistas en restauración de objetos de arte.

Se da así una incidencia mixta de capitales, por un lado los públicos (el Servicio) y por otro los privados (Tarea). A ellos se van sumando los apoyos de los municipios de la región, en lo económico, pero fundamentalmente en la mano de obra y en el apoyo moral (cofradías, feligreses, etc. que preparan fiestas y otras celebraciones). El municipio toma también la responsabilidad del mantenimiento posterior a las obras. Entre otros lugares intervenidos se hallan Uquía, Casabindo y Huacalera.

\section{Los pasos posteriores a la restauración}

Tres son los temas que tendremos en cuenta en este capítulo: el mantenimiento continuo, la revisacin de lo restaurado y por último los aspectos de actual consideracin en América Latina y que serán continuos objetos de análisis en los próximos años en lo que respecta a la restauración.

Sobre el tema del mantenimiento algo hemos dicho en capítulos anteriores. Hemos centrado nuestra atención sobre el hecho de que, previamente a la restauración de un monumento, debe quedar en claro quién se hará cargo del mantenimiento del mismo en el futuro. Debe diferenciarse lo que es una obra privada -donde de por sí el propietario asumirá la mayor parte de la responsabilidad- de lo que es una pública -en donde hay que dejar bien definido quién se adjudicará tales compromisos-.

Es imprescindible, ya durante la restauración, utilizar soluciones técnicas que favorezcan tales mantenimientos en el porvenir, colocando materiales adecuados y que posean un fácil escurrimiento de las aguas en el caso de los edificios, o protegiendo debidamente las salas de los museos cuando se trata de objetos de arte.

Se considera actualmente indispensable -más allá de si se cumple o no- una revisión periódica de las intervenciones en restauración, cada 
cinco, diez o quince años según el caso. Esto surge de la necesidad de verificar el acierto o no en las técnicas utilizadas.

Esta propuesta fue presentada por el arquitecto brasileño Ciro Correia Lima en el Cuarto Congreso Nacional de Preservación realizado en Corrientes (Argentina) en octubre de 1988.

Los interventores deben entender que las soluciones no son definitivas, que existen materiales que a primera vista parecen buenos pero que los años demuestran su incompatibilidad con los componentes originales de los edificios. Ejemplo de lo dicho pueden ser las obras de restauración en las que se utilizó el hierro, sustancia que con los años fue oxidándose dañando los monumentos más de lo que estaban.

Otro caso es el del silicato de etilo, consolidante que se emplea a través de un rociado y que ha sido utilizado en varios sitios arqueológicos del Perú, por ejemplo en Chan-Chan desde 1975. Al cabo de diez años el químico encargado de estos trabajos volvió al lugar y reparó en que el componente no había surtido efecto. Decidió entonces tomar una muestra para experimentar, comprobando entonces que el silicato se había evaporado por completo.

La vigilancia y la readecuacin, entonces, es fundamental; por ello es también importante que todas las intervenciones, como la señalada en el párrafo anterior, sean reversibles, es decir que si se comprueban errores en los trabajos sea posible repetir el proceso hasta lograr el punto conveniente.

En la actualidad otros dos problemas fundamentales se están debatiendo en Latinoamérica en el plano de la restauración. Ellos, comunes en gran medida a Europa, son el arreglo de las restauraciones mal hechas y el problema del deterioro de las obras de hormign armado. En el caso del primero, es problema que se está verificando especialmente en los edificios de finales del siglo XIX y principios del XX. Para ello es necesario no solo estudiar la obra sino también su historia material, analizando los documentos que han quedado de la época de la construcción primera y de las sucesivas etapas de agregados si es que las hubiera.

En lo que atañe al problema del deterioro de las obras de hormigón armado, los daños que están mostrando numerosas obras realizadas en ese material se deben a alteraciones químicas que anteriormente eran desconocidas y que se están comprobando en la actualidad. Estas 
verificaciones no solo se están produciendo en las obras nuevas sino también en las obras restauradas con dicho material. Existe además un alto porcentaje de probabilidad de que estas averías se constaten también en obras de ingeniería como puentes, presas hidroeléctricas, etc.

\section{Referências}

AA.VV. La comunicacin global del patrimonio Cultural. Gijón,: Trea, 2008.

AA.VV. Patrimonio Cultural y medios de comunicacin. Sevilla, Instituto Andaluz del Patrimonio Histórico, 2007.

AA.VV. Patrimonio inmaterial y gestin de la diversidad. Sevilla, Instituto Andaluz del Patrimonio Histórico, 2005.

AA.VV. Patrimonio y ciudad: reflexin sobre centros histricos. II Jornadas de Patrimonio de Priego de Córdoba. Sevilla, Instituto Andaluz del Patrimonio, 1994.

ABAD GONZÁLEZ, Luisa; El patrimonio cultural como factor de desarrollo: estudios multidisciplinares. Cuenca, Universidad de Castilla-La Mancha, 2006.

ALONSO IBÁÑEZ, M.R. El Patrimonio Histrico. Destino pblico y valor cultural. Madrid; Civitas, 1992.

BALLART, J. El patrimonio histrico y arqueolgico: valor y uso. Barcelona; Ariel, 1997.

BELLIDO GANT, Mạ Luisa. Arte, museos y nuevas tecnologas. Gijón: Trea, 2001.

BELLIDO GANT, Maㅡ Luisa (ed.). Aprendiendo de Latinoamrica. El 
museo como protagonista. Gijón: Trea, 2007.

BELLIDO GANT, M ${ }^{a}$ Luisa (ed.). Difusin del Patrimonio Cultural y nuevas tecnologas. Sevilla: Universidad Internacional de Andalucía. 2008.

CALVO MANUEL, A. M. Conservacin y restauracin: materiales, tcnicas y procedimientos: de la A a la Z. Barcelona: Serbal, 1997.

CAMPILLO GARRIGÓS, R. La gestin y el gestor del patrimonio cultural. Murcia: Editorial KR, 1998.

CASTRO MORALES, F., BELLIDO GANT, Ma ${ }^{a}$ L. (eds.). Patrimonio, Museos y Turismo cultural: claves para la gestin de un nuevo concepto de ocio. Córdoba, Universidad de Córdoba, 1998.

DE PAULA, A. S. J. "La preservación del patrimonio arquitectónico argentino (1850-1890)". En: Documentos de Arquitectura Nacional y Americana, Resistencia, junio de 1985, № 19, pp. 69-80.

GONZÁLEZ-VARAS, I. Conservacin de Bienes Culturales. Teora, historia, principios y normas. Madrid, Cátedra, 1999.

GUTIÉRREZ, R. "Identidad cultural y preservación del patrimonio". En: Boletn de la Secretara del Patrimonio Histrico y Artstico Nacional, SPHAN, Brasilia, № 24, 1983.

GUTIÉRREZ, R. "Responsabilidades frente al patrimonio arquitectónico y urbano". En: Anais do 1 Congresso Latinoamericano sobre a cultura arquitetnica, Porto Alegre, 1991.

HERNÁNDEZ HERNÁNDEZ, F. El Patrimonio cultural: la memoria recuperada. Gijón, Trea, 2002.

HERNÁNDEZ MARTíNEZ, A. Documentos para la historia de la restauracin. Zaragoza, Universidad de Zaragoza, 1999.

LÓPEZ JAEN, J. Curso de Rehabilitacin. O. Normativa Internacional. Madrid: Colegio Oficial de Arquitectos de Madrid, 1987. 
MARTÍN, M. (coord.) Difusin del Patrimonio Histrico. Sevilla, Instituto Andaluz del Patrimonio Histórico, 1996.

MORALES MIRANDA, J. Gua prctica para la interpretacin del patrimonio. El arte de acercar el legado natural y cultural al pblico visitante. Sevilla: Junta de Andalucía, 2001.

PARDO ABAD, Carlos J. Turismo y patrimonio industrial: un anlisis desde la perspectiva territorial. Madrid: Síntesis, 2008.

SENDRA, G. (coord.) Perfil y formacin de Gestores Culturales. Madrid: Ministerio de Cultura, 1995.

TARTARINI, J. D. "Rehabilitación: documentos para su estudio, I". En: Documentos de Arquitectura Nacional y Americana, Resistencia, 1989-1990, № 28/29, pp. 105-112.

VIÑUALES, G. M. Restauracin de Arquitecturas de Tierra. San Miguel de Tucumán, Instituto Argentino de Investigaciones de Historia de La Arquitectura y el Urbanismo, 1981.

VIÑUALES, G. M. Patrimonio arquitectnico. Aportes a la cultura nacional y americana. Buenos Aires: Instituto Argentino de Investigaciones de Historia de la Arquitectura y del Urbanismo, 1990. 


\section{Rodrigo Gutiérrez Viñuales}

Rodrigo Gutiérrez Viñuales nació en Resistencia (Argentina) el 19 de octubre de 1967. Profesor Titular de Historia del Arte de la Universidad de Granada (España). Ha impartido cursos de doctorado en las universidades de Granada, Zaragoza y Pablo de Olavide (España) y en las nacionales de Misiones y del Nordeste (Argentina). Ha dictado clases y dado conferencias por invitación en las citadas universidades y en las de Sevilla, La Laguna, Jaime I de Castellón y Complutense de Madrid (España), Federal de Goiás (Brasil), La Habana (Cuba) y Politécnica (Puerto Rico), además de hacerlo en numerosas instituciones públicas y privadas de España, Italia, México, Cuba, Puerto Rico, Colombia, Ecuador, Brasil, Paraguay, Argentina, Chile y Uruguay.

Coordinador de la Biblioteca y del Archivo de Arte Latinoamericano del Centro de Documentación de Arquitectura Latinoamericana (CEDODAL), Buenos Aires (Argentina). Coordinador de Iberoamérica y miembro del Comité Internacional de la Revista de Museologa, Madrid, desde 1998.

Especializado en arte iberoamericano de los siglos XIX y XX, ha publicado un centenar de estudios sobre estos temas, destacando entre sus últimos libros: Monumento conmemorativo y espacio pblico en Iberoamrica (Madrid, Cátedra, 2004), Arte Latinoamericano del siglo XX. Otras historias de la Historia (Zaragoza, Prensas Universitarias, 2005), Amrica y Espaa, imgenes para una historia. Independencias e identidad 1805-1925. (Madrid, Fundación MAPFRE, 2006). Comisario de varias exposiciones, siendo las más recientes: "Cultura funeraria y expresión artística en Iberoamérica" (Biblioteca de Andalucía, noviembre de 2006 y Funermostra-Feria de Muestras, Valencia, mayo de 2007), "Ecuador. Tradición y modernidad" (Biblioteca Nacional, Madrid, abril-agosto de 2007), "Arte Latinoamericano en la colección BBVA" (Palacio del Marqués de Salamanca, Madrid, septiembre-diciembre 2007), "Buenos Aires. Los escenarios de Luis Seoane" (octubre-diciembre de 2007) y "El reencuentro entre España y Argentina en 1910. Camino al Bicentenario" (Banco Provincia, Buenos Aires, 2007). 